Коновалова Татьяна Леонидовна, старший преподаватель кафедры «Экономическая теория и национальная экономика», Саратовский национальный исследовательский государственный университет имени Н.Г.Чернышевского. Россия.
410013, г. Саратов, ул. Астраханская, 89.

Тел.: (8452) 21-36-41.

Ключевъе слова: рынок труда; международная трудовая миграция; труд мигрантов в сельском хозяйстве.

\title{
MIGRATION PROCESSES IN THE RUSSIAN LABOR MARKET
}

Konovalova Tatyana Leonidovna, Senior Teacher of the chair "Economic Theory and National Economics", Saratov National Research State University named after N.G. Chernyshevskiy. Russia.

Keywords: labor market; the international labor migration; work of migrants in agriculture.
The condition of the Russian labor market in which important place is allocated for the workers involved from abroad is considered. The problems of functioning of modern labor market and a problem arising in connection with involvement of foreign labor - both qualified specialists, and workers of low qualification are allocated. Special attention is paid to use of work of migrants in agriculture.

\section{МЕТОДОЛОГИЧЕСКИЕ ПОДХОДЫ К ИССЛЕДОВАНИЮ РЕСУРСНОГО ПОТЕНЦИАЛА СЕЛЬСКОХОЗЯЙСТВЕННЫХ ПРЕДПРИЯТИЙ}

\author{
МАКУХИНА Анастасия Васильевна, Саратовский государственный аграрный университет \\ имени Н.И. Вавилова
}

\begin{abstract}
Анализируются методологические подходы к исследованию ресурсного потенииала сельскохозяйственных предприятий. При этом обоснована необходимость первоочередного использования синергетического и системного подходов. Выявлена взаимосвязь между всеми методологическими подходами, применяемыми как на промышленных, так и на сельскохозяйственных предприятиях. Выявлены основные факторы, влияющие на эффективность управления их ресурсным потенциалом. Рассмотрен механизм управления ресурсным потенщиалом сельскохозяйственного предприятия в разрезе его системной сущности, раскрыто его понятие и значение.
\end{abstract}

Введение. Ресурсный потенциал предприятия, согласно общепринятому мнению, - это совокупность его возможностей по производству товаров и оказанию услуг, которая включает в себя внутренние переменные и управленческий потенциал. В рыночной экономике потенциал предприятия зависит от внутренних факторов и от спроса потребителя, экономической ситуации в стране, действий конкурентов и других факторов. Ресурсы представляют собой не что иное как материальную основу начала производства. В зависимости от характера производства и его технологических особенностей ресурсы могут позволить получение разных по объему, эффективности и качественных характеристик конечных результатов труда. Такой подход к категории «ресурсы», послужил основанием для ученых присоединить их к расходной части процесса производства, т.е. ресурсы характеризуют лишь то, что может быть использовано, а не то, что может быть получено в результате осуществления производственного процесса. Иными словами, ресурсы представляют собой диалектическую противоположность результатам производства. Они обусловливают результаты, находятся с ними в неразрывном единстве, но не тождественны им [18]. Целью данного исследования является выявление необходимых методологических подходов к анализу процесса управления ресурсным потенциалом сельскохозяйственных предприятий. При этом автор понимает под методологией совокупность приемов и методов исследования, применяемых в различных науках.

Актуальность исследования данной темы обусловлена изучением методологических подходов к исследованию ресурсного потенциала, применимых на сельскохозяйственных предприятиях, главная задача которых - обеспечение продовольственной безопасности страны в условиях политики импортозамещения [12]. Для рассмотрения показателей предприятия необходимо использовать некоторые методологические подходы к формированию механизма управления ресурсным потенциалом. В данной работе рассмотрены такие методологические подходы, как синергетический, системный, генетический и динамический, воспроизводственный, процессный, функциональный, комплексный и ситуационный.

Теоретическая и практическая ценность системного подхода к организации была продемонстрирована Б. Ливихудом и Ф. Глазлом в исследовании «Динамическое развитие предприятия» [3]. Согласно их мнению, предриятие - это результат сложного взаимодействия факторов внешнего и внутреннегомираи одновременнопродукт деятельности человека продукт деятельности человека. Современная теория функционирования организаций формировалось начиная с конца девятнад- 
цатого века и прошла ряд этапов. В классической техно-структурной теории организации Ф.У. Тейлор обосновал и структурировал отдельные функциональные элементы и заложил основу исследования процесса специализации производственного процесса. На основе этого сформировалась рационально-управляемая организация хода дел [14].

Одной из главных задач исследования является рассмотрение существующих методологических подходов к эффективному функционированию сельскохозяйственными предприятиями, в том числе особенностей методов, применяемых в аграрном секторе (см. таблицу).

Методика исследований. В основу исследования легли труды зарубежных классиков экономической мысли в теории организации производства и управления $[2,3,4,5,14,15]$. Автором сделана попытка адаптировать основные тезисы теории применительно к специфике с.-х. производства и в первую очередь основные методологические подходы к исследованию ресурсного потенциала аграрных организаций.

Результаты исследований. Понятия ресурсы и ресурсный потенциал включают в себя различные виды вещественно-энергетических, важнейшие из которых вода, почва, солнечная энергия, минеральные вещества и ряд других, формируются естественно-природным путем, а также те, которые создаются человеком - финансы, машины, механизмы, удобрения; в связи с глобализацией экономики первостепенное значение среди последних приобрел инновационно-информационный компонент.

Ресурсный потенциал существует вне сферы производства, при этом уже готовый в ней участвовать в определенных объемах. Он формируется из всего наличия ресурсов в определенных комбинациях, которые соответствуют потребностям предстоящего производственного процесса [9].

Среди ресурсов важнейшей составляющей являются финансовые прямые методы, без которых немыслим любой процесс производства. В том числе:

льготное кредитование;

частичное покрытие затрат производителя за счет роста цен по ряду показателей;

краткосрочный кредит на товар;

различные виды кредитования организаций АПК, поступающие из регионального и федерального бюджетов; государственные гарантии возврата денежных средств кредитным организациям

помощь в осуществлении лизинга необходимой c.-х. техники, помощь в поиске денежных средств

денежное финансирование развития инфраструктуры села

субсидии в рамках государственной поддержки сельского хозяйства и перерабатывающих предприятий АПК;

финансирование природоохранительной и природо-восстановительной работ;

налоговые льготы на доходы с.-х. предприятий.

Мировые и российские тенденции развития современной экономики свидетельствуют о необходимости инновационного обеспечения деятельности всех форм хозяйствования на селе, что, в свою очередь, должно привести к росту их производительности и эффективной деятельности всех видов аграрного предпринимательства. Не последнюю роль при этом играет эффективное включение ресурсного потенциала в сферу с.-х. производства.

Когда ресурсный потенциал включается посредством инновационных технологий и организационных форм в процессы производства и начинает функционировать в производстве, он приобретает новые качества и находит выражение в категории «факторы». В экономической науке факторы производства определяются как диалектическое единство ресурсного потенциала и технологий его использования [10]. Результат и качество работы управления предприятием видны, прежде всего, при выборе метода решения проблем, в том числе, таких как подходы, принципы, методы. Без знания теории практика не даст эффективных результатов. Но к менеджменту возможно применить не все принципы и подходы, несмотря на то, что в настоящее время известны более четырнадцати научных подходов. Для реализации поставленных целей рассмотрим каждый методологический подход, с учетом их синергетической взаимосвязи применительно к сельскому хозяйству.

Для более глубокого исследования потенциала сельскохозяйственных предприятий необходимо, по мнению автора, раскрыть циклическую динамику экономического потенциала предприятия. Впервые системно проанализировал экономические циклы и кризисы в 60-х гг. XIX в. К. Маркс [5]. Главной причиной этих явлений он считал проти-

Элементы ресурсного потенциала сельскохозяйственных предприятий

\begin{tabular}{|l|l|}
\hline \multicolumn{1}{|c|}{ Виды ресурсного потенциала } & \multicolumn{1}{|c|}{ Область применения } \\
\hline Технические ресурсы & Производственное оборудование, сырье, материалы \\
\hline Технологические ресурсы & Способы изготовления продукции \\
\hline Кадровые ресурсы & Численность и квалификация кадров \\
\hline $\begin{array}{l}\text { Инновационно- } \\
\text { информационные ресурсы }\end{array}$ & $\begin{array}{l}\text { Сведения о системе и внешней среде, новейших технологиях, } \\
\text { объеме перерабатываемой информации, ее достоверность и своевременность }\end{array}$ \\
\hline Финансовые ресурсы & Величина и использование денежных средств, финансовое состояние предприятия \\
\hline Организационные ресурсы & Применяемые способы принятия решений, организация системы планирования, контроля и т.д. \\
\hline $\begin{array}{l}\text { Агроклиматические } \\
\text { и почвенно-земельные ресурсы }\end{array}$ & Совокупность земель, используемых в сельском хозяйстве \\
\hline Водные ресурсы & Водные запасы, используемые для мелиорации и содержания скота \\
\hline Растительно-кормовые ресурсы & Зерно, сено, фураж, используемые для кормления скота \\
\hline
\end{tabular}


воречие между общественным характером производства и частнокапиталистическим характером присвоения его результатов, то есть возникновение кризисов тесно связано с процессом перенакопления основного капитала. Значительный вклад в теорию цикличности сделал российский ученый M. Туган-Барановский, который в своей работе «Периодические промышленные кризисы. История английских кризисов. Общая теория кризисов» связывал экономический цикл с оборотом капитала [15]. По мнению ученого, периодическое оживление и застой в капиталистическом хозяйстве вызваны быстрым накоплением свободного капитала и неорганизованностью производства. Одними из основных работ, раскрывающих сущность циклического развития, считаются работы советского экономиста-агрария Н. Кондратьева и австрийского ученого Й. Шумпетера [19]. Характеризуя циклические колебания экономической конъюнктуры, ученые утверждали, что большие циклы проявляются в едином процессе динамики экономического развития, в котором выделяются средние и малые циклы с фазами подъема и кризиса

Процессный подход к управлению был впервые предложен сторонниками школ административного управления, которыми были разработаны функции управления. Однако эти авторы рассматривали функции как независимые друг от друга. В противоположность этому процессный подход рассматривает функции управления как взаимосвязанные действия. Управление как работа по достижению целей с помощью других - это не какое-то единовременное действие, а серия непрерывных взаимосвязанных действий, т.е. процесс. Эти действия, каждое из которых само по себе является процессом, по сложившейся научной традиции, называются функциями управления.

В отличие от процессного подхода к управлению системный подход рассматривает взаимозависимость не функций управления, а отдельных частей организации, ее структурных подразделений, а также взаимозависимость организации и окружающей среды. Он четко граничит с теоретическими знаниями в области систем, помогающими принимать значимые решения в управлении предприятием. Большой вклад в развитие системного подхода был внесен зарубежными учеными: Дж. Лорш, П. Лоуренс и др. [4]. Системный подход - это не набор каких-то руководящих и инструктивных материалов или принципов для руководителей, а способ мышления по отношению к организации и управлению. Система - некоторая целостность, состоящая из взаимозависимых частей, каждая из которых характеризует целое. Любая организация также является системой. Наиболее крупные важные части организации как системы называются подсистемами, которые в свою очередь могут состоять из более мелких подсистем. Так как все они взаимосвязаны, то неправильное функционирование даже самой незначительной из них может отрицательно сказаться на эффективности деятельности системы в целом [11].
Системный подход к управлению должен быть применим, по мнению автора, в любой организации, в том числе аграрной сферы.

Важным аспектом системного подхода является функциональный подход. Название данного подхода говорит само за себя. Первоначально необходимо понять, в какой продукции, в каком товаре или услуге нуждается потребитель и после этого составить необходимый план действий, рассмотреть конкретные функции предприятия, необходимые для достижения оптимального результата. Данное положение прежде всего применимо к с.-х. сырью и продовольственным товарам, которые призваны удовлетворять первоочередные потребности населения.

Другим не менее важным аспектом системного подхода является комплексный. В основе данного подхода лежит следующий принцип: при принятии важных решений управления должны учитываться значимые факторы внешней и внутренней среды предприятия, такие как экономические, технологические, организационные, социальные, психологические, политические и ряд других.

Необходимым аспектом в рамках системного анализа является генетический подход, который подразумевает детальное изучение деятельности как промышленных, так и аграрных предприятий в прошлом, составляется анализ за несколько предшествующих лет [13]. На основе полученных данных прогнозируется деятельность предприятия в будущем. Другими словами, при этом подходе предприятие - это продукт, который анализируют, готовят и прогнозируют, чтобы потом «вынести» для потребителя.

При воспроизводственном подходе происходит постоянное производство товара, способное удовлетворить потребителя и их потребности, не допуская высоких затрат, но, и не снижая качества конечной продукции. Воспроизводственный подход направлен на постоянное обновление производствапродукцииснаименьшейресурсоемкостью и высоким качеством по сравнению с аналогичной продукцией на данном рынке для удовлетворения потребностей населения. В основе данного подхода лежит рассмотрение его горизонтального и вертикального срезов производственных отношений в рамках с.-х. производства. Воспроизводственный подход направлен на то, чтобы определить границы горизонтального среза, включающего в себя такие показатели, как производство, распределение, потребление, обмен. Вертикальный срез позволяет рассмотреть изучаемую область на микро-, макро-, мезо- и мегауровнях.

Ситуационный подход наиболее часто применяют к управлению предприятием. Он разработан в конце 60-х гг. ХХ в., его главная особенность заключается в том, что он не отвергает действующие теории управления. Еще в 1920-е гг. М.Ф. Фоллетт «вывела» «закон ситуации», она отмечала, что «различные ситуации требуют различных типов знаний», и руководитель, обладающий знаниями 
применительно только к одной ситуации, даже в хорошо управляемой организации, является «калифом на час» [16]. В 1948 г. Р. Стогдилл пришел к выводу, о том, что именно конкретная ситуация в большей степени определяет, какие черты и навыки необходимы руководителю [10]. Ученый подчеркивает значимость «ситуационного мышления». Центральным тезисом ситуационной теории является понятие и «ситуация», т.е. конкретный набор факторов (обстоятельств), которые сильно влияют на степень эффективности использования ресурсов предприятия. Принцип «работы» ситуационного подхода можно сравнить с деятельностью специалиста-конфликтолога на предприятии. Если в какой-то области функционирования организации произошел сбой, возможно применение этого подхода для его устранения. Это касается всего производства в целом и отношений между работниками, руководством и подчиненными. Главная цель этого подхода - разобраться в конкретной ситуации, устранить возникшие проблемы и позволить предприятию работать в полную силу без ущерба для производства.

Важным методологическим аспектом при исследовании данной темы является синергетический подход. При исследовании экономической эффективности использования ресурсов необходимо выделить точки роста сельскохозяйственных предприятий, опираясь на которые можно простимулировать эффективное их развитие. Необходимо использовать анализ ресурсов на микро-, мезо- и макроуровнях и выделить точки роста. Синергетика - это наука, занимающаяся изучением процессов самоорганизации и возникновения, поддержания, устойчивости и распада структур самой различной природы. Как считал Г. Хакен, профессор института синергетики в г. Штутгарте, синергетика занимается изучением систем, состоящих из большого числа частей, компонентов и подсистем, деталей, сложным образом взаимодействующих между собой [17]. Синергетический подход предполагает согласованность функционирования всех элементов предприятия, что в конечном счете, отражается на функционировании самой системы как единого целого. Основное понятие синергетики определение структуры как состояния, возникающего в результате поведения многоэлементарной или многофакторной среды не демонстрирующей стремления к усреднению. По мнению автора, создание и функционирование АПК есть нечто иное, как реализация принципов синергетического подхода применительно к трем сферам данного комплекса - производство средств производства для сельского хозяйства и перерабатывающей промышленности, сельскохозяйственного производства и перерабатывающей промышленности.

Заключение. Таким образом, методологической основой для рассмотрения данной темы стали научные подходы к эффективному использованию ресурсного потенциала с.-х. предприятий, в том числе, такие как динамический, синергетический, ситуационный и процессный, а также системный (с его основными аспектами - генетическим, воспроизводственным, функциональным, комплексным). Применение каждого из подходов позволяет рассмотреть сельскохозяйственное предприятие как механизм, систему процессов, в основе которых стоит деятельность человека. Невозможно функционирование организации с применением какого-то одного подхода, на деятельность предприятия влияет много факторов. Все методологические подходы взаимосвязаны между собой и их применение происходит как по отдельности, так и одновременно.

\section{СПИСОК ЛИТЕРАТУРЫ}

1. Вдовин С.М., Салимова Т.А., Бирюкова Л.И. Система менеджмента качества организации: учеб. пособие. - М., 2012 - 299 с.

2. Кейнс Дж. Общая теория занятости процента и денег. - New York, 1936. - 472 с.

3. Ливехуд Б., Глазл Ф. Динамическое развитие предприятия. Как предприятия-пионеры и бюрократия могут стать эффективными. - Режим доступа: dic. academic.ru>book.nsf.

4. Лоуренс П.Р., Лорш И.В. Организация и окружающая среда: управление дифференциацией и интеграцией. - Бостон, 1967. - 322 с.

5. Маркс К. Капитал. - М., 2016. - 636 с.

6. Маслак О. Оценка циклической динамики экономического потенциала промышленного предприятия // Общество и экономика. - 2013. - № 3. - С. 134-137.

7. Общие подходы к управлению производством // Управление и оптимизация производственного предприятия. - Режим доступа: producm.ru/production/ general-approaches-to-the-management-of-production.

8. Резепов М.Ю. Ресурсный потенциал: понятие, механизм регулирования. - Саратов, 2004. - 44 с.

9. Резник С.Д. Менеджмент в социальных и экономических системах: теория и методология: учеб. пособие. - М., 2013. - 304 с.

10. Стогдилл Р. Справочник по лидерству. Обзор теории и исследований. - New York, 1974. - 287 c.

11. Судомир С.M. Результативность системы управления предприятиями // АПК: экономика, управление. - 2014. - № 8. - С. 81-86.

12. Суханова И.Ф., Алиев М.И., Лявина М.Ю. Актуальные проблемы ценообразования на региональном рынке зерна и хлебопродуктов в условиях импортозамещения // Аграрный научный журнал. - 2016. № 1. - C. $75-79$.

13. Суханова И.Ф. Производственные основы Содружества независимых государств. - Саратов, 1999. - 132 с.

14. Тейлор Ф.У. Принципы научного менеджмента. - М., 1991. - 104 с.

15. Туган-Барановский М.И. Периодические промышленные кризисы. История английских кризисов. Общая теория кризисов. - Смоленск, 1923. - 430 с.

16. Фоллетт М.Ф. Конструктивный конфликт. New York, 1940. - 349 c.

17. Хакен Г., Стендтлер М. Синергетика познания. Берлин, 1981. - 268 с.

18. Шаталова Т.Н., Шишкина Л.Г. Основные методологические принципы оценки ресурсного потенциала сельскохозяйственных предприятий // Аграрная экономика в период модернизации российского общества. - Саратов, 2001. - С. 96-97.

19. Шумпетер Й. Теория экономического развития. - М., 2007. - 864 с. 
Макухина Анастасия Васильевна, соискатель ученой степени, Саратовский государственный аграрный университет имени Н.И. Вавилова. Россия.

410012, г. Саратов, Театральная пл., 1.

Тел.: (8452) 26-27-83.
Ключевъе слова: ресурсный потенциал; методологические подходы; сельскохозяйственные предприятия; агропромышленный комплекс.

\title{
METHODOLOGICAL APPROACHES FOR RESEARCH OF THE RESOURCE POTENTIAL OF AGRICULTURAL ENTERPRISES
}

Makuhina Anastasia Vasilievna, Competitor, Saratov State Agrarian University named after N.I Vavilov. Russia.

Keywords: resource potential; methodological approaches; agricultural enterprises; agro-industrial complex.

The article is devoted to the consideration of methodological approaches to the study of the resource potential of agricultural enterprises. The necessity of detailed consideration of each approach is shown. The necessity of using the synergistic and system approaches is substantiated. The interrelation between all methodological approaches applied at the enterprises is revealed. The methodology of research of approaches used in agricultural enterprises is singled out. The main factors influencing the efficiency of managing the resource potential of enterprises are identified. The mechanism of managing the resource potential of an agricultural enterprise as a single mechanism is considered; its concept and significance are disclosed.

удк 338.436.316.334

\section{ИНФОРМАЦИОННЫЕ ТЕХНОЛОГИИ В РОССИЙСКИХ ОБРАЗОВАТЕЛЬНЫХ УЧРЕЖДЕНИЯХ КАК ВАЖНЕЙШИЙ РЕСУРС РАЗВИТИЯ ОТЕЧЕСТВЕННОЙ ЭКОНОМИКИ}

\author{
САРАНЦЕВ Владимир Николаевич, Московский университет имени С.Ю. Витте \\ ТУПОЛьСКАЯ Татьяна Николаевна, Московский университет имени С.Ю. Витте
}

Рассматриваются актуальные проблемы информатизации российского общества и в частности образовательного процесса как важного условия инновационного развития российской экономики. Анализируется ряд противоречий методологического, педагогического, научного свойства российской системы высшего образования в русле эволюции современного информационного общества. Обосновывается взаимодействие бизнеса, государства и вузовской науки. Эффективное применение информационно-коммуникационных технологий (ИКТ) в образовательном процессе значительно повысит его эффективность.

Введение. Экономические успехи, лидерство в мировой экономике и уровень общественного благосостояния зависят от того, в какой степени экономика страны готова и способна к производству и распространению информации и знаний [15]. По мнению американских ученых, в век информации знания, а не материальные активы или финансовые ресурсы являются ключом к конкурентоспособности [3], т.е. от информационной составляющей бизнеса зависят дальней шее развитие предприятия, эффективное функционирование производственного процесса, место товаров на рынке и многое другое [14]. Знания, квалификация, опыт, навыки человека представляют собой существенный ресурсный фактор, влияющий на развитие экономики в целом, развитие которой в настоящее время переходит на качественно новый уровень, где в достижение высоких социально-экономических результатов решающее значение приобретают именно знания и информационные технологии как инструменты работы с знаниями. Целью данного исследования является анализ выявления проблем информатизации российского общества и в частности системы образования и возможности их разрешения.

Методика исследований. Научные исследования проводились на базетрудов ведущих отечествен- ных и зарубежных ученых как в области взаимосвязи системы высшего образования и инновационной экономики $[1,2,3,8,14,18,19]$, так и эффективного использования информационно-коммукационных технологий в отечественных вузах $[4,5.6,9,12$, 17]. Авторами были использованы методические и справочные материалы, нормативно-правовые акты государственных власти, в том числе федеральные законы и государственные программы [7, 11, 16]. Основными методами исследования были диалектический; анализа и синтеза; экономико-статистический и проблемно-хронологический.

Результаты исследований. Как было отмечено выше, современная экономика - это экономика знаний, основанная на потоке инноваций. На постоянном технологическом совершенствовании и производстве высокотехнологичной продукции с высокой добавленной стоимостью. Ключевым продуктом экспорта на глобальные рынки становятся не товары, а сами технологии. Именно такой тип экономики обеспечивает мировое экономическое превосходство страны Повышение инновационной активности и переход на инновационный тип развития зафиксирован в Стратегии инновационного развития Российской Федерации на период до 2020 года, конечная цель которой - обеспечение 